\title{
Instantiating Abstract Knowledge to Deepen Students' Understanding
}

\author{
Dong Hua, Ce Zhang, Jun Bai \\ School of Computer Science and Technology \\ Harbin Institute of Technology at Weihai \\ Weihai, China \\ e-mail: huahd@hotmail.com
}

\begin{abstract}
This paper explores the importance of instantiating abstract knowledge to students' learning. It takes the course of Computer Organization as an example and presents some practice-tested methods and real cases of abstract knowledge teaching, aiming to discuss what a college teacher should do to effectively help his/her students deepen their understanding of abstract concepts, theories and principles, which is indispensable for them to enter into a higher phase of learning in the future.
\end{abstract}

Keywords-instantiation, abstract, Computer Organization, inclass teaching

\section{INTRODUCTION}

In addition to its use value of making educational activities progress smoothly, in-class teaching, as an art, possesses a high aesthetic value due to its creativity and sensuousness. Teachers should learn and utilize the skills of in-class teaching in order that these values can be fully achieved. Teaching in class is a comprehensive, dynamic process, not only very demanding for teachers, but also requiring that students actively participate in and respond to it. Whether this response exists and how well it could be are largely determined by teachers. Therefore, teachers are the key element of in-class education.

Many college courses focus on theory rather than practice, and are thus hard to understand. On the other hand, these courses enhance students' academic literacy and lay a solid foundation for them, which are both beneficial and essential to the furthering of their studies. Accordingly, a teacher should carefully make an educational design for each class, expressing the obscure contents in the textbook with plain, straight language and illustrating it via vivid examples. Among those simplifying and instantiating methods are the using of simile, analogy, and inspiring. These methods have been adopted by the author in several successive semesters' lecturing on Computer Organization, and have made the classes active and the students responsive. As a result, they have become deeply aware of the content taught in class. Following are some experiences.

\section{RESPECT StUdents, BRING THEIR TALENTS INTO FULl Play, AND ACTIVATE THEIR CREATIVITY}

Different from those of junior/senior high school, classes in college are attended by cognitively independent students, each one being an individual who possesses high capability of analysis, judgment, and self-learning. Therefore, if a college teacher is merely devoted to distributing information, if their teaching materials stick rigidly to textbooks without their own characteristic analysis and description, if they fail to activate students' creativity and desire for knowledge, this educational activity will be vulgar rather than spectacular, boring rather than attracting, and thus a definite failure. The activeness of a college class is of vital importance, owing to the fact that learners' potential needs this positive atmosphere in order to be unleashed. Therefore, teachers should dive into students' mind, put themselves in the students' position, and adopt appropriate teaching strategies to arise their eager for learning. To do this, one must respect their students, rank their students first on their list of priorities; understand them, trust them, be ready to encourage them, forgive them; treat them equally and appreciate their individualism. Chances of participating in the educational activity should be given to each student, making them feel that they, instead of being a mere information receiver, also play an important role in class. A good teacher talks equally with their students, assuming absolutely no air of condescension; values them, giving them a sense of independence - in other words, students in class should be made to feel as if they are discussing problems with friends after class, so that they can without any distraction take part in this teaching \& learning activity, and be fully devoted to the absorbing of knowledge.

The essence of education is to realize each learner's full potential and help them shape their own unique character. Modern college students are very individualistic and independent-minded. As a college educator, one must be well aware of these new features, act as both an instructor and a friend, so that the students' learning can be promoted. In the eyes of a college student, their teacher should be familiar and easy-going, whose status being the same as their own. It is only against this background that students' talents and creativity can be brought into full play.

With these aforementioned ideas in mind, a teacher is now probably able to effectively communicate and interact with their students in class.

\section{FIND INSTANCES AND TRY YOUR BEST TO DO ON- THE-SPOT TEACHING}

\section{A. Teaching on the spot can be effective}

Terms such as CPU, memory, bus, I/O interface, and computer architecture are repeatedly encountered in Computer Organization. In order to clarify the objective of 
this course at the very beginning, I found a waste computer in my lab, carried it to the classroom, put it on the table, opened it, and showed each of its components to the class, telling them what they were and which stages of development they were in. The whole class was found to be very active, students very attentive and excited. Some of them even walked straight to the platform to check out the details, and raised some realistic questions. Then I assembled the separate parts together right in front of the class, and told them that this course is meant to explain the basic organization and principles of such a PC; moreover, it will expand these ideas to a computer in general. Thanks to this vivid in-class demonstration, the students now had gained a perceptual understanding of computer organization; the psychological barriers to the learning of basic hardware had been removed, and future teaching \& learning were guaranteed from the outset.

\section{B. Confirm knowledge in the textbook with real applications}

Integrating theory with practice is always a helpful strategy, especially for engineering courses, whose books are full of "empty" stuff, making learners feel rather unsure. When teaching the lesson of virtual memory, I had emphasized over and over again that "virtual memory is a technology of using the space of hard disks to make up for the space shortage of RAM." I thought the students had understood, but later I realized that they actually had not. Therefore, I took Windows XP as an example, and showed them how the operating system manages the memory system.

I started Windows Task Manager (see Fig. 1), pointed out that $788 \mathrm{MB}$ is the size of my physical memory in use. The operating system, however, thought my computer had a total memory of $1878 \mathrm{MB}$. So where does this extra $1090 \mathrm{MB}$ come from? Back to the root directory of my system drive, I spotted the virtual memory file, pagefile.sys, and checked that its size was exactly $1090 \mathrm{MB}$. Through this illustration, the students became convinced of the existence of virtual memory, and in addition learned something inside Windows. Again in this process, students were fully mobilized. Some of them talked about their own realizations of virtual memory as well as of system configuration, to which I withheld no praise and encouragement. I further communicated with them and accordingly made deeper explanation of the textbook. The result was quite satisfactory.

\section{DRAW ANALOGIES FROM REAL LIFE TO REDUCE THE DIFFICULTY OF LEARNING}

\section{A. Create fitting scenarios, skillfully use similes to teach difficult knowledge in an easy way}

During the lecturing of Computer Organization, teachers should not only explain the principles, but also help their students grasp the essence of each point. As a matter of fact, all human knowledge is objective, while each learner has their own unique understanding of it. The variation can be great. Consequently, only when one injects their own feelings in the understanding of an objective - in particular, obscure - knowledge, can we be reassured that they may deeply comprehend it; otherwise, the apparent understanding probably means complete ignorance, or, even if they get some points in class, they will again get lost after the bell is rung.

Take the explaining of bus and its hierarchical architecture as an example. If a teacher merely says that bus is the pathway of information communication among the major components of a computer system, that bus has some features, and that modern buses are organized into a

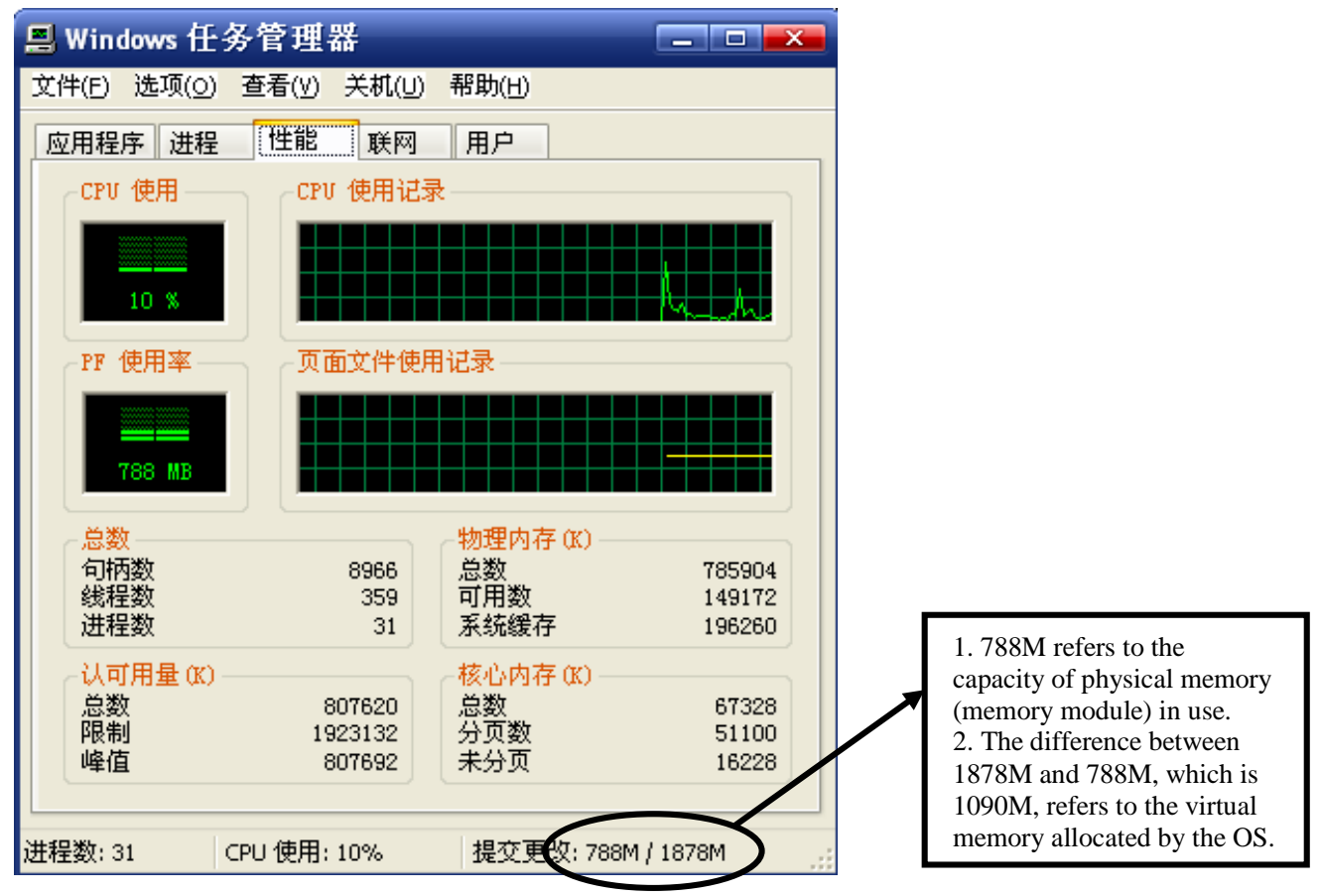

Figure 1. Windows XP Task Manager 
hierarchy, many students will feel uncertain about it and doubt its existence. Here we can well liken buses to the roads through which we travel every day: without them it is hard for people to communicate. Besides, if the teacher can show the class a photo of a modern computer's motherboard, pointing out that the slots for PCI cards, EISA cards, and memory modules, etc. are interfaces for system integration and expansion, then the students' impression will be vivid, concrete and deep-rooted. As to the hierarchy of buses, we can compare them to the various kinds of roads in our country: expressway, national road, urban street, rural path, etc. Advanced cars like Mercedes-Benz and BMW run on expressways so that their capacity can be put to good use; carts driven by cattle can only travel along rural dirt track. What if we want to transport cattle from one city to another? The answer is by packing them into a container and then using a lorry to carry it through expressways. Similarly, buses in a computer system are arranged into several levels according to the transmission rate of the components they link: CPU, a high-speed part, communicates via a high-speed bus; while slow devices such as keyboard or mouse transmits through a low-speed one; and if we want to send data from a slow input device to a high-speed module like the memory, we should gather these scattered data into a larger block, and transmit it as a whole via high-speed bus. This analogy draws the students a clear picture of the hierarchical structure of buses.

There are some necessary conditions for a successful simile-using education: the teacher must fully comprehend the knowledge to be taught, carefully organize the teaching materials, find an appropriate analogy, and use simple language to express it. So long as one gets well prepared, they are sure to feel easy and comfortable in class. As to the stuff of similes, they are generally drawn from observations and experiences of everyday life.

When teaching the three ways of interfacing I/O devices to CPU/memory, i.e. polling, interrupt-driven I/O, and DMA (Direct Memory Access), I found it hard for students to understand the essence and differences of these three methods. Then I likened the mechanism to the system of student management in Chinese colleges, the general idea of which is that students are organized into "classes" on their entry into the college, and these classes usually are not reorganized during their whole college life, acting as a basic unit while attending most of the college activities. There is a teacher taking charge of such a class. If the teacher always go and ask if the students have any problems, this is polling; if they stay in an office, and any student with some problems can go to them for help, this is like interrupt-driven $\mathrm{I} / \mathrm{O}$; if they appoint a monitor to deal with the class's daily affairs, this is called DMA. In this evolution, the teacher is gradually relieved of busy management tasks, and thus can be devoted to their own business. Similarly, in the development of the mechanism controlling the communication between I/O devices and CPU/memory, the burden of data I/O on CPU is reduced, so it can focus on its own job, i.e. data processing. As a result, the efficiency gets improved. This analogy succeeded in turning an abstract problem into something realistic and familiar, and deepened the students' comprehension of this complicated problem.

\section{B. Change the narrative point of view and use conversational tone to increase affinity}

Traditionally, during in-class education, the teacher lectures alone on the contents of the textbook, objectively and narratively. This emotionless way of teaching is rather tedious. Research has shown that if the lecturer uses, instead of a boring tone, the first person in a conversation-like explanation to the students, the effect can be improved by around $40 \%$. An even more effective method is by telling stories, with simple and familiar language. Another thing to be noticed is that one should not be too serious on the platform. Just imagine two people standing in front of you, one interesting, whom you met at a dinner party; one nerdy, who keeps preaching all the time. Which do you prefer? The answer is, of course, the former, because they are more attractive and more easy-going, and this affinity can shorten the psychological distance between teacher and student. Teaching and learning supplement each other. The closer the teacher gets to the students, the more responsive the students become to the teacher. This is why familiarity plays a positive role in education.

\section{The Visualizing of ABstract KnOWLEDGE Aids MEMORY}

\section{A. Increase the proportion of pictures in the teaching materials to help students remember}

Compared with plain texts, pictures make it easy for people to memorize the information they convey. Due to the self-evidence of pictures, the efficiency of in-class learning can be improved by as high as $89 \%$. A good picture ensures the smooth and effective running of a class. It says so much more than teachers' words, and thus is extremely helpful for the explaining of abstract knowledge. Therefore, one should make more and better use of such materials as graphs, images, and animated pictures as their means of teaching.

Two's complement representation is one of the most basic points of computer science. Its essence is to use addition to replace subtraction. This is, of course, an exceptionally clever thought, but for college students who have little theoretical knowledge about computer, this thought is hard to get accustomed to: why are negative numbers denoted in this way? Given the two's complement representation of a number $x$, why can we get the two's complement representation of its additive inverse simply by inverting every 0 to 1 and every 1 to 0 , then adding one to the result? Can addition really be used in place of subtraction? These facts seem either strange or contradictive with the knowledge the students have already learned, so they may easily feel suspicious, or even worried. If the teacher don't lend them a helping hand to remove their suspicion, their confidence of learning will probably get damaged, which will in turn affect the following process of education.

Therefore, we can introduce two's complement representation by reminding the students of a clock, and show them a clock-face-resembled circle (only that it has a 
scale of 16 rather than 12) such as Fig. 2, telling them this is a small counting system with 16 as its modulus. Then, they are made to consider which values should these 16 binary numbers each denote. Of course, we can imitate the clock and let $0000 \sim 1111$ represent $0 \sim 15$ respectively; however, in order to realize subtraction, we should allocate some of them to negative values. For instance, 1111 can be seen as moving clockwise from 0 by 15 points $(0+15)$, or alternatively, as moving anti-clockwise from 0 by 1 point $(0$ -1 ); thus in this counting system, 15 is equivalent to -1 . Therefore, human beings, well adapted to the beauty of symmetry, use $0000 \sim 0111$ to represent $0 \sim 7$, and $1111 \sim$ 1001 to denote $-1 \sim-7$. There, however, remains another question: should 1000 mean 8 or -8 ? In light of the fact that until now, all negative numbers have 1 as their leftmost bit, while all non-negative numbers 0 , the answer should be -8 . This is how two's complement representation comes into being (see Fig. 3). Besides, it is obvious from the picture that, for any value $\mathrm{x}$ other than 0 and -8 , which should be dealt with exceptionally, $[\mathrm{x}]_{\mathrm{two}}+[-\mathrm{x}]_{\mathrm{two}}=10000$. Here we ask, what do you find in this pair of binary numbers? Many students, after a thought, will come to realize that each of the two must be the result of inverting every bit of the other and adding one. Finally, when doing subtraction, for example 5 3 , or $5+(-3)$, we add the two's complement representation of 5 (0101) and that of -3 (1101), discarding the carry out from the leftmost bit just as a clock does, and get the result 0010, which is exactly the two's complement representation of 2 .

Thanks to the appropriate use of graphs, the abstract, strange mathematical concept has been turned into a concrete, familiar image in the students' minds. Although its truth

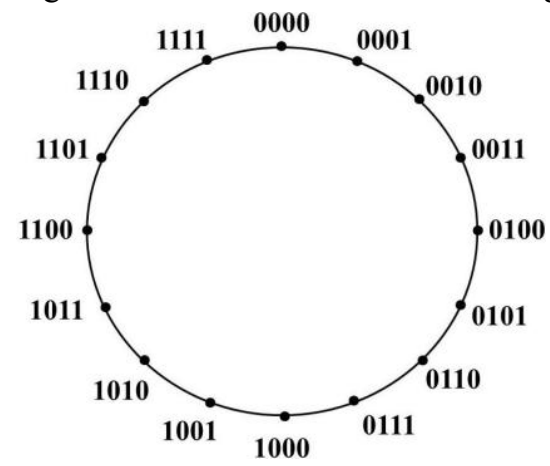

Figure 2. A modulo-16 counting system

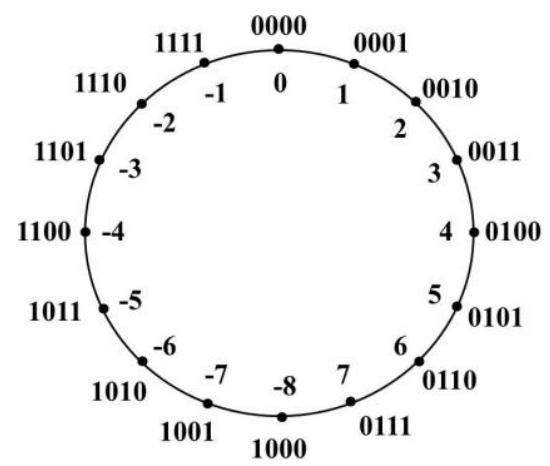

Figure 3. A picture-rendering of two's complement representation has not yet been proved in a strict mathematical way, their suspicion no longer exists, and the confidence, or even interest, of grasping two's complement representation has been cultivated.

\section{B. Use animated pictures to make comprehensive illustration}

As an automaton, computer executes programs in a dynamic, consecutive way, whereas most teachers merely rely on words to describe this process. One major weakness of this method is its lack of visibility and vividness, which in turn results in a faint impression and shallow understanding in students' minds. If we can use pictures to reproduce the process of a computer working, the effect will be excellent. At present, multimedia teaching usually takes the following forms:

1) Video clip.

2) Flash file.

3) Animated gif or .jpg file.

4) Block diagram shown dynamically.

No matter which technology one adopts, so long as they add visibility to their teaching, the students will easily be impressed.

\section{CONCLUSION}

As the saying goes, methods in teaching are available, unlimited but worth selecting. Educators should carefully learn from their own teaching practice as well as the experiences of others, use their initiative and bring their creativity into full play, find similarities between teaching stuff and daily life, and choose the best strategy according to the content to be taught, the condition of the students, and the context of the class.

\section{ACKNOWLEDGMENT}

This paper is funded by the program of computer hardware course series of Harbin Institute of Technology at Weihai (ITEA10002002).

\section{REFERENCES}

[1] Craig Zilles, "'What does a CPU have in Common with a Fast Food Restaurant?' A Reflection on Emphasizing the Big Ideas of Computer Science in a Computer Organization Class," $35^{\text {th }}$ ASEE/IEEE Frontiers in Education Conference, Session S3C, pp. 11-14, October 2005.

[2] Xuesong Zhang, "Enhancing Teaching of Computer Organization through Concrete Examples and Laboratory Experiences," Proceedings of $20094^{\text {th }}$ International Conference on Computer Science \& Education, pp. 1357-1362.

[3] Tianzhou Chen, Guanjun Jiang, Wei Hu, and Xueqing Lou, "The Innovation and Reformation of Teaching Method for Computer Organization and Design Course," International Conference on Information Engineering and Computer Science, 2009, pp. 1-4.

[4] Anguita M, Fernazdez B, "Software optimization for improving student motivation in a computer architecture course," IEEE Trans. Educ., 2007, 50(4), pp. $373-378$.

[5] David A. Patterson and John L. Hennessy, Computer Organization and Design: The Hardware / Software Interface, $4^{\text {th }}$ edition, Number ISBN: 0123747503, Morgan Kaufmann. 